\title{
Prevalence Of Potentially Inappropriate Medication In The Older Adult Population Within Primary Care In Portugal: A Nationwide Cross-Sectional Study
}

This article was published in the following Dove Press journal: Patient Preference and Adherence

\author{
Pedro Augusto Simões (D) 1,2 \\ Luiz Miguel Santiago (iD) ${ }^{3-5}$ \\ Katia Maurício ${ }^{3}$ \\ José Augusto Simões (1D) $1,6,7$
}

'Faculty of Health Sciences, University of Beira Interior, Covilhã, Portugal; ${ }^{2}$ ARS Centro, USF Pulsar, Coimbra, Portugal; ${ }^{3}$ University of Coimbra, Faculty of Medicine, Coimbra, Portugal; ${ }^{4}$ University of Coimbra, General Practice/Family Medicine University Clinic of the Faculty of Medicine, Coimbra, Portugal; ${ }^{5}$ University of Coimbra, CEISUC Center for Health Studies and Research, Coimbra, Portugal; ${ }^{6}$ ARS Centro, USF Caminhos Do Cértoma, Mealhada, Portugal; ${ }^{7}$ University of Porto, CINTESIS Centre for Research in Health

Technologies and Service, Oporto, Portugal
Background: In potentially inappropriate medications harm potentially outweighs benefits. Even appropriately prescribed medications may become inappropriate. They can lead to a high risk of adverse drug reactions, morbidity and mortality. The aim of this study was to determine the prevalence of potentially inappropriate medication in the older adult population attending primary care in Portugal and to identify associated sociodemographic and clinical factors.

Methods: We conducted a cross-sectional, analytical study in primary care centres from the five Portuguese healthcare administrative regions and the two autonomous regions. We used a random sample of 757 older patients provided by the information department of the ministry of health (SPMS) and family doctors from the autonomous regions. Data collection occurred March 2018 and we studied sociodemographic characteristics, clinical profile and medication. We used 2015 Beers Criteria to assess potentially inappropriate medications. Logistic regression analyses were performed to determine associations between potentially inappropriate medications' prescriptions and other variables.

Results: Potentially inappropriate medication was present in $68.6 \%$ and $46.1 \%$ of the sample had two or more. The likelihood of having potentially inappropriate medication increased significantly with being female $(\mathrm{OR}=1.56$ [1.05 to 2.31]), number of chronic health problems $(\mathrm{OR}=1.06$ [1.01 to 1.13$])$, number of pharmacological subclasses $(\mathrm{OR}=1.40$ [1.30 to 1.51]) and number of prescribers $(\mathrm{OR}=1.34$ [1.09 to 1.65$])$. Proton-pump inhibitors, nonsteroidal anti-inflammatory drugs and benzodiazepines were the most commonly found ones.

Conclusion: Potentially inappropriate medication in older adults was found to be a common occurrence in Portugal. It is important that doctors are aware of this problem, namely in the primary care setting due to the longitudinal care.

Keywords: potentially inappropriate medication, aged, polypharmacy, multimorbidity

\section{Background}

Potentially inappropriate medications (PIM) are those in which harm potentially outweighs the benefits, namely those that are not indicated or lack evidence of efficacy and those that do not align with patients goals/preferences and values. ${ }^{1}$ The importance of this increases as people get older because of decreased hepatic and renal function that changes the benefit/risk ratio of medications, so even when appropriately prescribed medications can become inappropriate. ${ }^{2,3}$ An Australian study reported that 60 of 100 hospitalized patients had at least one PIM, leading to a high risk of adverse drug reactions, morbidity and mortality. ${ }^{4}$ There is an international consensus about when to
Correspondence: Pedro Augusto Simões ARS Centro, USF Pulsar, Rua Teófilo Braga, $n^{\circ} 255^{\circ}$ Dto, Coimbra 3030-076, Portugal

Tel +35I 239968384396

Email pedro.augusto.simoes@ubi.pt 
start many medications that are safe and effective, but there are no guidelines regarding the cessation of inappropriate medications. ${ }^{5}$

Many medication screening tools were developed to aid identification of PIMs in older adults and improve their care. ${ }^{6-8}$ The medication screening tools can be divided into explicit checklists (lists of medications to be avoided in older adults) and implicit checklists (issues to be taken into account before prescribing a medication). ${ }^{9}$ The most widely used are Beers criteria ${ }^{10}$ and the STOPP/START criteria (STOPPscreening tool of older persons potentially inappropriate prescriptions/START-screening tool to alert doctors to right treatment). ${ }^{11}$ The Medication Appropriateness Index is an example of an implicit checklist. ${ }^{9}$

Older patients, particularly those aged 65 and over, are more frequently diagnosed with more pathologies, multimorbidity, and conditions prone to involve more prescription drugs. ${ }^{12,13}$

In Portugal, there are only studies about the prevalence of PIM in some of its regions, none conducted nationwide. ${ }^{14,15}$ The most recent study in a primary care health centre in north of Portugal identified a $37.0 \%$ prevalence of PIM, more frequent in women $(40.7 \%)$ than in men $(30.9 \%){ }^{14}$

The aim of this study was to identify the nationwide prevalence of PIM in older adults, identified in primary care setting, in Portugal and its sociodemographic and clinical profiles.

\section{Materials And Methods Study Design}

Cross-sectional study-details, definitions and methods were previously published. ${ }^{16}$

The study was conducted in agreement with the principles of the Declaration of Helsink $\mathrm{i}^{17}$ and received ethical approval from University of Beira Interior and Portuguese healthcare administrative regions Institutional Ethics Committees. The reporting of this study conforms to the Strengthening the Reporting of Observational Studies in Epidemiology (STROBE) statement. ${ }^{18}$

\section{Sampling}

Since there were 2.18 million older adults ( $\geq 65$ years) in Portugal and the national literature suggested that the range of PIM is around $40 \%$ and the international literature around $60 \%$, we assumed the rate to be over $50 \%$ because of epidemiological concern for better evidence and larger sampling. We estimated a sample of a minimum
742 patients for a $95 \% \mathrm{CI}$ and a maximum precision error of $5 \%$. In agreement with the geographical distribution of the Portuguese population aged 65 and older across the five mainland healthcare administrative regions and the two autonomous regions (Madeira and Azores), noted in PORDATA, ${ }^{19}$ a random sample of 757 patients was provided by the information department of the ministry of health, Serviços Partilhados do Ministério da Saúde (SPMS), and invited family doctors from autonomous regions, due to lack of digital databases within these last regions.

\section{Data Collection Procedures}

Data collection occurred in March 2018 (data extracted on March 30). In brief, the SPMS provided us with an electronic file with the variables of the study from the randomly selected (by patient's national health number) sample of the five healthcare administrative regions. This electronic file contained anonymised information stored in the patient's electronic medical records. Since SPMS does not have access to electronic medical records from patients in the two autonomous regions, we invited two medical doctors, one from each autonomous region, to provide us with the needed information. We studied the prescribed medications using the mandatory nationwide, electronic prescription platform (PEM). ${ }^{20}$ There is an unknown number of over the counter medications consumed by the Portuguese population and as they can be bought without prescription, there is no way to access this information. SPMS could not provide us with information regarding the level of education, since in most cases it was missing from medical records.

\section{Outcome Variable}

For each patient, PIM was measured as the presence of one or more drugs, that are inappropriate for older patients, according only to Table 2 of 2015 Beers Criteria. ${ }^{10}$

\section{Independent Variables}

Sociodemographic characteristics such as age, gender (male/ female), area of residence (in terms of health administrative region), clinical profile (chronic health problems according to International Classification of Primary Care, second edition - ICPC-2) and prescribed medication (from April 2017 to March 2018 and was encoded following the Portuguese pharmacotherapeutic classification using the more discriminate level possible). The Portuguese pharmacotherapeutic classification has similarities with the ATC (Anatomical Therapeutic Chemical) classification and was adapted by 
INFARMED (National Authority of Medicines and Health Products). ${ }^{21}$

\section{Statistical Analysis}

In addition to the descriptive analysis, $\chi^{2}$ tests were performed for nominal qualitative characteristics. Lastly, we performed a logistic regression with all the statistically significant variables in previous $\chi^{2}$ tests. All tests were two-sided using a significance level of 0.05 . Statistical analysis was conducted using SPSS V.24.0.

\section{Results}

\section{Characteristics Of Participants}

The sample consisted of 757 individuals; the mean age was of $75.5 \pm 7.9$ years $(75.1 \pm 7.9$ years for men and $75.8 \pm 7.8$ years for women). Table 1 shows the characteristics of the sample.

\section{Prevalence Of Potentially Inappropriate Medication}

More than 9 of 10 older patients of the sample (93.4\%) had at least 1 medication prescribed, with an overall average of 8.2 (95\% CI 7.9 to 8.6 ), 7.5 (95\% CI 7 to 8 ) in men and 8.8 (95\% CI 8.3 to 9.3$)$ in women.

Potentially inappropriate medication was present in $68.6 \%$ (95\% CI $65 \%$ to $72 \%$ ) of the sample and 2 or more PIMs were present in $46.1 \%$ (95\% CI $42.5 \%$ to $49.7 \%$ ), with an overall average of 1.76 (95\% CI 1.63 to $1.89), 1.35$ (95\% CI 1.18 to 1.52$)$ in men and 2.07 (95\% CI 1.88 to 2.26 ) in women.

According to Table 2, there was no significant relationship between PIM and health administrative region. There was a significant relationship between PIM and number of chronic health problems, number of medications taken, number of prescribers and with many of the ICPC-2 classes and pharmacological subclasses.

After adjustment, Table 3 shows that the likelihood of having PIM increased significantly in females $[\mathrm{OR}=1.56$ (1.05-2.31)], with number of chronic health problems $[\mathrm{OR}=1.06(1.01-1.13)]$, number of pharmacological subclasses $[\mathrm{OR}=1.40(1.30-1.51)]$ and number of prescribers $[\mathrm{OR}=1.34(1.09-1.65)]$. No differences in the odds of PIM were associated with age $[\mathrm{OR}=0.99(0.97-1.05)]$.

\section{Chronic Health Problems/Pharmacological Subclasses And Patterns Of PIM}

Table 3 shows the odds ratio measured the impact of having each specific chronic health problems (according to ICPC2).
Table I Characteristics Of The Sample

\begin{tabular}{|c|c|}
\hline Characteristic & Total \% (n) \\
\hline \multicolumn{2}{|l|}{ Gender } \\
\hline Women & $56.8(430)$ \\
\hline Men & $43.2(327)$ \\
\hline \multicolumn{2}{|c|}{ Health Administrative Region } \\
\hline North & $32.2(244)$ \\
\hline Centre & $25.1(190)$ \\
\hline Lisbon-Tejo Valley & $27.7(210)$ \\
\hline Alentejo & $8.7(66)$ \\
\hline Algarve & $4.5(34)$ \\
\hline Madeira & $0.9(7)$ \\
\hline Azores & $0.8(6)$ \\
\hline \multicolumn{2}{|l|}{ Age } \\
\hline$<75$ years & $51.5(390)$ \\
\hline$\geq 75$ years & $48.2(365)$ \\
\hline \multicolumn{2}{|c|}{ Number of Chronic Health Problems } \\
\hline $0-2$ & $17.3(131)$ \\
\hline $3-4$ & $19.3(146)$ \\
\hline $5-6$ & $17.6(133)$ \\
\hline $7-8$ & $16.8(127)$ \\
\hline $9-10$ & $11.9(90)$ \\
\hline$\geq 11$ & $17.2(130)$ \\
\hline \multicolumn{2}{|c|}{ Chronic Health Problems (ICPC2) } \\
\hline$A$ & $11.2(85)$ \\
\hline B & $7.5(57)$ \\
\hline $\mathrm{D}$ & $36.5(276)$ \\
\hline $\mathrm{F}$ & $20.5(155)$ \\
\hline $\mathrm{H}$ & II.5 (87) \\
\hline $\mathrm{K}$ & $77.5(587)$ \\
\hline $\mathrm{L}$ & $51.8(392)$ \\
\hline $\mathrm{N}$ & 15.7 (I19) \\
\hline$P$ & $34.3(260)$ \\
\hline $\mathrm{R}$ & $23.4(177)$ \\
\hline S & $19.3(146)$ \\
\hline $\mathrm{T}$ & $68.6(519)$ \\
\hline$U$ & $21.5(163)$ \\
\hline$x$ & $9.5(72)$ \\
\hline Y & $15.2(115)$ \\
\hline Z & $3.6(27)$ \\
\hline \multicolumn{2}{|c|}{ Number of Pharmacological Subclasses } \\
\hline $0-4$ drugs & $23.1(175)$ \\
\hline $5-9$ drugs & $39.0(295)$ \\
\hline$\geq 10$ drugs & $37.9(287)$ \\
\hline \multicolumn{2}{|c|}{ Pharmacological Classes (INFARMED) } \\
\hline 2 & 74.5 (64) \\
\hline
\end{tabular}

(Continued) 
Table I (Continued).

\begin{tabular}{|l|l|}
\hline Characteristic & Total \% (n) \\
\hline 3 & $81.8(619)$ \\
4 & $36.9(279)$ \\
5 & $21.1(160)$ \\
6 & $50.6(383)$ \\
7 & $16.5(125)$ \\
8 & $42.5(322)$ \\
9 & $53.9(408)$ \\
10 & $20.3(154)$ \\
16 & $1.6(12)$ \\
\hline Number of Prescribers & \\
\hline$\leq 2$ & $63.9(484)$ \\
$>2$ & $36.1(273)$ \\
\hline
\end{tabular}

Notes: A, general and unspecified; B, blood, blood forming organs, lymphatics, spleen; D, digestive; F, eye; $H$, ear; $K$, circulatory; L, musculoskeletal; $N$, neurological; P, psychological; R, respiratory; S, skin; T, endocrine, metabolic and nutritional; $U$, urology; $X$, female genital system and breast; $Y$, male genital system; $Z$, social problems; 2 , central nervous system; 3 , cardiovascular system; 4, blood; 5 , respiratory system; 6 , digestive system; 7 , genitourinary system; 8 , hormones and medications used to treat endocrine diseases; 9, locomotive system; 10, antiallergic medication; 16, antineoplastic and immunomodulatory drugs.

For patients suffering from chronic health problems related to digestive, circulatory, musculoskeletal and respiratory systems, there are 1.4 times, 1.2 times, 1.3 times and 1.5 times, respectively, greater probability of having a PIM when comparing to those not suffering from health problems related to that specific system. Older adults taking medication from central nervous system, digestive system and locomotive system groups (according to Portuguese pharmacotherapeutic classification) are 2.4 times, 4.9 times and 5.3 times, respectively, more likely to have PIM than those not taking any drug from that system group. The most common pharmacological subclasses causing PIM were proton-pump inhibitors (present in $45.6 \%$ of the sample), nonsteroidal anti-inflammatory drugs (in 34.5\%) and benzodiazepines (in 27.3\%).

\section{Discussion}

\section{Strengths Of The Study}

This is the first study to report the prevalence and patterns of PIM in older adults attending primary care consultations nationwide in Portugal. It is a cross-sectional study with a randomised sample, which is the most frequent design to assess the prevalence and its characteristics. We used the most discriminative chemical subgroup of the Portuguese pharmacotherapeutic classification, to assess polypharmacy; this can minimize the bias of medical changes. We also used active components according to 2015 Beers
Criteria $^{10}$ for assessing PIM, since for some pharmacological classes some active pharmaceutical ingredients are potentially inappropriate while others are safe.

Since the data were obtained from SPMS on a nationwide scale, we could obtain a size representative sample of the population, avoiding over-representation of the more frequent users of primary care services, which could happen if the data were collected from GP records of most frequent prescriptions.

\section{Statement Of Overall Findings}

The study results show a high prevalence of PIMs in the Portuguese older population $(68.6 \%)$, exceeding the reported prevalence of other studies $(11.5-62.5 \%) .^{22}$ One of the explanations can be the period of time we used in this study (12 months), which can increase polypharmacy ${ }^{23}$ and affect the number of PIM, making this high prevalence misrepresentative of reality, since the medication could have been ceased or not purchased. Given the lack of consensus of classification for PIM, ${ }^{6}$ we used the list of drugs in Table 2 of 2015 Beers Criteria. We used Beers Criteria because it is the most commonly used tool to identify PIM in the literature with regular updates.

We found no difference in risk of PIM with increasing age. Our findings do not match those from other studies; most of them found an increased risk of PIM in younger and older ages. $^{22,24}$ Since there are mixed results, more studies are needed to assess this relation. One hypothesis for this discrepancy is that there is a higher awareness of this problem in overall patients with $\geq 65$ years due to increased susceptibility to adverse drug events, age-related drug-drug and drugdisease interactions, making it possible to think that there is no difference in pharmacological care in people equal and older than 65 in Portugal as age increases. ${ }^{25}$

In line with previous reports, ${ }^{22}$ we found an increased risk of PIM in women. We can hypothesise that women tend to live longer and be more prone to have complaints, either physical or psychological. More studies are necessary to study this issue.

As expected, the number of medications affects the number of PIMs, since with an increased number of drugs there is an increased probability of adverse drug reactions and drug-drug interactions. This association is described in the literature. ${ }^{22,24,26}$

We found a difference in risk of PIM with the number of comorbidities, showing the impact that multimorbidity also affects the health of older adult population through the increased risk of PIM. ${ }^{12}$ Our results again do not match 
Table 2 Prevalence Of PIM According To Characteristics

\begin{tabular}{|c|c|c|c|c|}
\hline Characteristic & No PIM \% (n) & PIM \% (n) & p-Value $\left(\chi^{2}\right.$ Test $)$ & Mean Number Of PIMs $(95 \% \mathrm{CI})$ [Median] \\
\hline \multicolumn{3}{|l|}{ Gender } & $<0.001$ & \\
\hline Women & $32.3(139)$ & $67.7(291)$ & & 2.07 (1.88 to 2.26$)[2]$ \\
\hline Men & $47.7(156)$ & $52.3(171)$ & & 1.35 (1.18 to 1.52$)[1]$ \\
\hline \multicolumn{3}{|c|}{ Health Administrative Region } & 0.201 & \\
\hline North & $32.0(78)$ & $68.0(166)$ & & $1.66(\mathrm{I} .44$ to $\mathrm{I} .89)[\mathrm{I}]$ \\
\hline Centre & $31.1(59)$ & $68.9(131)$ & & 1.85 (1.59 to 2.12$)[1]$ \\
\hline Lisbon-Tejo Valley & $28.9(58)$ & $71.1(152)$ & & $2.00(1.75$ to 2.26$)[2]$ \\
\hline Alentejo & $37.9(25)$ & $62.1(4 I)$ & & $\mathrm{I} .38(0.95$ to $\mathrm{I} .8 \mathrm{I})[\mathrm{I}]$ \\
\hline Algarve & $44.1(15)$ & $55.9(19)$ & & $1.32(0.53$ to 2.11$)[1]$ \\
\hline Madeira & $42.9(3)$ & $57.1(4)$ & & 0.57 (0.08 to 1.07$)[1]$ \\
\hline Azores & $0(0)$ & $100(6)$ & & 2.33 (1.25 to 3.42$)[2]$ \\
\hline \multicolumn{3}{|l|}{ Age } & 0.048 & \\
\hline$<75$ years & $34.6(135)$ & $65.4(255)$ & & $\mathrm{I} .70(\mathrm{I} .52$ to $\mathrm{I} .88)[\mathrm{I}]$ \\
\hline$\geq 75$ years & $27.9(102)$ & $72.1(263)$ & & $1.83(1.64$ to 2.03$)[1]$ \\
\hline \multicolumn{3}{|c|}{ Number of Chronic Health Problems } & $<0.001$ & \\
\hline $0-2$ & $54.2(7 \mathrm{I})$ & $45.8(60)$ & & I.I 4 (0.85 to I.42) [0] \\
\hline $3-4$ & $43.8(64)$ & $56.2(82)$ & & $1.40(1.10$ to 1.70$)[1]$ \\
\hline $5-6$ & $30.1(40)$ & $69.9(93)$ & & $1.65(1.33$ to 1.96$)[1]$ \\
\hline $7-8$ & $18.9(24)$ & $81.1(103)$ & & 2.08 (1.76 to 2.40$)[2]$ \\
\hline $9-10$ & $25.6(23)$ & $74.4(67)$ & & $1.83(1.47$ to 2.20$)[2]$ \\
\hline$\geq 11$ & $12.3(16)$ & $87.7(114)$ & & 2.55 (2.22 to 2.89$)[2]$ \\
\hline \multicolumn{5}{|c|}{ Chronic Health Problems (ICPC2) } \\
\hline A & $22.4(19)$ & $77.6(66)$ & 0.063 & 2.07 (1.66 to 2.49 ) [2] \\
\hline B & $24.6(14)$ & $75.4(43)$ & 0.299 & 1.91 (1.40 to 2.43$)[1]$ \\
\hline $\mathrm{D}$ & $21.0(58)$ & $79.0(218)$ & $<0.001$ & 2.14 (1.90 to 2.38$)[2]$ \\
\hline $\mathrm{F}$ & $27.1(42)$ & $72.9(113)$ & 0.208 & 2.06 (1.74 to 2.37$)[2]$ \\
\hline $\mathrm{H}$ & $21.8(19)$ & $78.2(68)$ & 0.049 & $2.2 \mathrm{I}$ ( 1.80 to $2.6 \mathrm{I})$ [2] \\
\hline $\mathrm{K}$ & 29.1 (17I) & $70.9(416)$ & 0.012 & I.82 (I.67 to 1.97$)[1]$ \\
\hline $\mathrm{L}$ & $23.2(91)$ & $76.8(301)$ & $<0.001$ & 2.06 (1.86 to 2.25$)$ [2] \\
\hline $\mathrm{N}$ & $21.8(26)$ & $78.2(93)$ & 0.018 & 2.29 (1.93 to 2.65$)$ [2] \\
\hline$P$ & $22.7(59)$ & $77.3(201)$ & $<0.001$ & 2.21 ( 1.97 to 2.46 ) [2] \\
\hline $\mathrm{R}$ & $19.8(35)$ & $80.2(142)$ & $<0.001$ & 2.19 (1.91 to 2.47$)$ [2] \\
\hline$S$ & $27.4(40)$ & $72.6(106)$ & 0.275 & $\mathrm{I} .72(\mathrm{I} .45$ to 1.99$)[\mathrm{I}]$ \\
\hline $\mathrm{T}$ & $27.9(145)$ & 72.1 (374) & 0.002 & $1.83(1.67$ to 1.99$)[1]$ \\
\hline$U$ & $23.3(38)$ & $76.7(125)$ & 0.013 & 1.94 (1.67 to 2.20$)$ [2] \\
\hline$x$ & $18.1(13)$ & $81.9(59)$ & 0.011 & 2.22 (1.79 to 2.66$)$ [2] \\
\hline$Y$ & $28.7(33)$ & $71.3(82)$ & 0.515 & $1.67(1.34$ to 2.00$)[1]$ \\
\hline Z & $14.8(4)$ & $85.2(23)$ & 0.089 & 2.30 (1.58 to 3.01$)$ [2] \\
\hline \multicolumn{3}{|c|}{ Number of Pharmacological Subclasses } & $<0.001$ & \\
\hline $0-4$ drugs & 73.7 (129) & $26.3(46)$ & & 0.35 (0.25 to 0.45$)[0]$ \\
\hline $5-9$ drugs & $29.2(86)$ & $70.8(209)$ & & $1.42(1.27$ to 1.58$)[1]$ \\
\hline$\geq 10$ drugs & $8.0(23)$ & $92.0(264)$ & & $2.97(2.73$ to 3.21$)[3]$ \\
\hline \multicolumn{5}{|c|}{ Pharmacological Classes (INFARMED) } \\
\hline 2 & $17.9(101)$ & $82.1(463)$ & $<0.001$ & 2.21 (2.05 to 2.36$)[2]$ \\
\hline
\end{tabular}


Table 2 (Continued).

\begin{tabular}{|c|c|c|c|c|}
\hline Characteristic & No PIM \% (n) & PIM \% (n) & p-Value ( $\chi^{2}$ Test) & Mean Number Of PIMs $(95 \% \mathrm{Cl})$ [Median] \\
\hline 3 & $26.0(161)$ & $74.0(458)$ & $<0.001$ & 1.94 (1.79 to 2.09$)[2]$ \\
\hline 4 & $19.7(55)$ & $80.3(224)$ & $<0.001$ & 2.14 (1.91 to 2.37 ) [2] \\
\hline 5 & I8.I (29) & $81.9(131)$ & $<0.001$ & 2.43 (2.12 to 2.73 ) [2] \\
\hline 6 & $8.6(33)$ & $91.4(350)$ & $<0.001$ & 2.78 (2.58 to 2.98 ) [2] \\
\hline 7 & $28.0(35)$ & $72.0(90)$ & 0.400 & I.89 (I.55 to 2.22$)$ [I] \\
\hline 8 & $22.4(72)$ & $77.6(250)$ & $<0.001$ & $2.02(1.80$ to 2.23$)$ [2] \\
\hline 9 & $10.3(42)$ & $89.7(366)$ & $<0.001$ & 2.51 (2.33 to 2.70 ) [2] \\
\hline 10 & $14.3(22)$ & 85.7 (I32) & $<0.001$ & $2.5 \mathrm{I}$ (2.22 to $2.8 \mathrm{I})$ [2] \\
\hline 16 & $8.3(1)$ & 91.7 (II) & 0.117 & 2.83 (I.28 to 4.39 ) [2] \\
\hline \multicolumn{3}{|c|}{ Number of Prescribers } & $<0.001$ & \\
\hline$\leq 2$ & $42.8(207)$ & $57.2(277)$ & & 1.24 (I.10 to 1.38$)[1]$ \\
\hline$>2$ & II.4 (3I) & $88.6(242)$ & & 2.69 (2.46 to 2.92 ) [2] \\
\hline
\end{tabular}

Notes: A, general and unspecified; B, blood, bloodforming organs, lymphatics, spleen; D, digestive; F, eye; H, ear; K, circulatory; L, musculoskeletal; N, neurological; P, psychological; R, respiratory; S, skin;T, endocrine, metabolic and nutritional; $U$, urology; X, female genital systemand breast; $Y$, male genital system; Z, social problems; 2, central nervoussystem; 3, cardiovascular system; 4, blood; 5, respiratory system; 6, digestivesystem; 7, genitourinary system; 8 , hormones and medications used to treatendocrine diseases; 9 , locomotive system; 10, antiallergic medication; 16, antineoplasticand immunomodulatory drugs.

those from other studies. Differences in the pharmacological and health problems data collection could explain such discrepancies. ${ }^{24,26}$ However, an increase number of comorbidities can lead to and can be the cause of an increase number of prescribed drugs, increasing the risk of PIM. ${ }^{12}$ From the four ICPC-2 classes with high impact on the risk of PIM according to our finding (digestive, cardiovascular, musculoskeletal and respiratory problems), only the musculoskeletal problems are described in the literature. ${ }^{26}$

In line with previous reports, ${ }^{27}$ more prescribers were associated with higher risk for PIM. One hypothesis is that prescribers may not be aware of all the medication the patient is taking nor of the changes made by other prescribers to the list of medication; this increases the risk of duplicated drugs, adverse drug reactions, drug-drug interactions and drug-disease interactions. On the other hand, more complex patients (with multiple comorbidities) need to be assisted by more doctors and take more drugs, increasing the risk of PIM. This is of extreme importance, since $17 \%$ of our older adults had 4 or more prescribers within the last year. It is also important for previously prescribed medication to be listed for everyone on the national electronic drug prescription system (PEM).

According to previous reports, ${ }^{24,26}$ PPIs, NSAID and benzodiazepines are among the most common PIM in the older adult population in primary health care in Portugal. Therefore, there is a need to quantify the resulting harms for individuals, families and society, and to make its economic and financial impact known to medical and lay communities, in order to help deprescribing to become easier for doctors and better accepted by patients.

\section{Limitations Of The Study}

There are some limitations of this study.

Firstly, we used a 12-month period to assess the chronicprescribed medication, which can increase the prevalence of polypharmacy and PIM, since medication could have been ceased or not purchased. Therefore, the number of medications, as well as the number of PIMs, per older adult may be overestimated.

Secondly, since the SPMS could not give us data from both autonomous regions (Madeira and Azores), representing $1.7 \%$ of the sample, data were collected by local GPs, making the sample and collection data processes in these two regions different from the rest. Nevertheless, randomisation was performed.

Thirdly, there was the intention of evaluating the effect of level of education on polypharmacy. Such was not possible due to lack of information in patient's electronic records.

Fourthly, we only used Table 2 of 2015 Beers Criteria for assessing PIM; therefore, PIM due to drug-disease and drugdrug were not assessed due to the complexity of this analysis and our 12-month period assessment of prescribed medication. Also, the Beers criteria were updated in April 2019, where some drugs were eliminated from and others added to the previous list (2015 Beers Criteria), but since at the time of study (2018), the most recent list was 2015 Beers criteria we kept them. 
Table 3 Adjusted Analysis For Factors Associated With PIM Use

\begin{tabular}{|c|c|c|c|}
\hline \multirow[t]{2}{*}{ Characteristics } & \multicolumn{3}{|l|}{ PIM } \\
\hline & OR & $95 \% \mathrm{Cl}$ & p-Value \\
\hline \multicolumn{4}{|l|}{ Gender } \\
\hline Women & 1.56 & 1.05 to 2.31 & 0.026 \\
\hline Men & base & - & - \\
\hline Age & 0.99 & 0.97 to 1.05 & 0.512 \\
\hline Number of Chronic Health Problems & 1.06 & 1.01 to 1.13 & 0.028 \\
\hline A & 0.88 & 0.52 to 1.48 & 0.632 \\
\hline $\mathrm{D}$ & 1.41 & 1.11 to 1.78 & 0.004 \\
\hline $\mathrm{H}$ & 0.94 & 0.56 to 1.58 & 0.814 \\
\hline $\mathrm{K}$ & 1.23 & 1.04 to 1.45 & 0.014 \\
\hline $\mathrm{L}$ & 1.27 & 1.10 to 1.48 & 0.001 \\
\hline $\mathrm{N}$ & 1.16 & 0.79 to 1.70 & 0.455 \\
\hline$P$ & 1.29 & 0.99 to 1.66 & 0.052 \\
\hline $\mathrm{R}$ & 1.49 & 1.09 to 2.04 & 0.014 \\
\hline $\mathrm{T}$ & 1.17 & 0.99 to 1.38 & 0.056 \\
\hline$U$ & 1.19 & 0.88 to 1.60 & 0.253 \\
\hline$x$ & 1.29 & 0.73 to 2.27 & 0.375 \\
\hline Number of Pharmacological Subclasses & 1.40 & 1.30 to 1.51 & $<0.001$ \\
\hline 2 & 2.35 & 1.95 to 2.84 & $<0.001$ \\
\hline 3 & 1.08 & 0.94 to 1.24 & 0.301 \\
\hline 4 & 0.94 & 0.65 to 1.36 & 0.749 \\
\hline 5 & 1.09 & 0.74 to 1.60 & 0.662 \\
\hline 6 & 4.86 & 3.18 to 7.42 & $<0.001$ \\
\hline 8 & 1.07 & 0.85 to 1.36 & 0.552 \\
\hline 9 & 5.25 & 3.53 to 7.81 & $<0.001$ \\
\hline 10 & 1.55 & 0.81 to 2.97 & 0.185 \\
\hline Number of prescribers & 1.34 & 1.09 to 1.65 & 0.005 \\
\hline
\end{tabular}

Notes: OR, odds ratio; A, general and unspecified; D, digestive;H, ear; K, circulatory; L, musculoskeletal; N, neurological; P, psychological;R, respiratory; T, endocrine, metabolic and nutritional; $U$, urology; $X$, female genitalsystem and breast; 2 , central nervous system; 3 , cardiovascular system; 4, blood;5, respiratory system; 6 , digestive system; 8, hormones and medications used totreat endocrine diseases; 9, locomotive system; 10, antiallergic medication.

Fifthly, the sample size was chosen to achieve a sufficiently precise overall proportion estimate of PIMs in the Portuguese older adults' population, but not to find differences among different population strata.

Finally, this is a cross-sectional study and so no causal relationship could be proven. However, we only intended to raise questions and not determine causality, so other studies are required to study causality, frequency and outcomes.

\section{Conclusion}

This study found a high prevalence of PIM in the studied sample; the most important factors were being female, number of chronic health problems, number of pharmacological classes and number of prescribers.
It is important that doctors are aware of this problem, namely in the primary care setting due to the longitudinal profile of care in general practice.

\section{Acknowledgments}

The authors thank the SPMS, Nivalda Pereira and Tânia Bairos for their participation in the data collection.

\section{Disclosure}

The authors report no conflicts of interest in this work.

\section{References}

1. Opondo D, Eslami S, Visscher S, et al. Inappropriateness of medication prescriptions to elderly patients in the primary care setting: a systematic review. PLoS One. 2012;7:e43617. doi:10.1371/journal. pone. 0043617 
2. Frank C. Deprescribing: a new word to guide medication review. CMAJ. 2014;186(6):407-408. doi:10.1503/cmaj.131568

3. Turner JP, Edwards S, Stanners M, Shakib S, Bell JS. What factors are important for deprescribing in Australian long-term care facilities? Perspectives of residents and health professionals. BMJ Open. 2016;6(3):e009781. doi:10.1136/bmjopen-2015-009781

4. Wahab MSA, Nyfort-Hansen K, Kowalski SR. Inappropriate prescribing in hospitalised Australian elderly as determined by the STOPP criteria. Int J Clin Pharm. 2012;34(6):855-862. doi:10.1007/s11096012-9681-8

5. Galazzi A, Lusignani M, Chiarelli MT, et al. Attitudes towards polypharmacy and medication withdrawal among older inpatients in Italy. Int J Clin Pharm. 2016;38(2):454-461. doi:10.1007/s11096016-0279-4

6. Whitman AM, DeGregory KA, Morris AL, Ramsdale EE. A comprehensive look at polypharmacy and medication screening tools for the older cancer patient. Oncologist. 2016;21(6):723-730. doi:10.1634/ theoncologist.2015-0336

7. Kaufmann CP, Tremp R, Hersberger KE, Lampert ML. Inappropriate prescribing: a systematic overview of published assessment tools. Eur J Clin Pharmacol. 2014;70(1):1-11. doi:10.1007/s00228-0141743-5

8. Spinewine A, Schmader KE, Barber N, et al. Appropriate prescribing in elderly people: how well can it be measured and optimised? Lancet. 2007;370(9582):173-184. doi:10.1016/S0140-6736(07)610 91-5

9. Samsa GP, Hanlon JT, Schmader KE, et al. A summated score for the medication appropriateness index: development and assessment of clinimetric properties including content validity. $J$ Clin Epidemiol. 1994;47(8):891-896. doi:10.1016/0895-4356(94)90192-9

10. Panel AGS. 2015 BCUE. American Geriatrics Society 2015 updated beers criteria for potentially inappropriate medications use in older adults. J Am Geriatr Soc. 2015;63(11):2227-2246. doi:10.1111/ jgs. 13702

11. O'Mahony D, O'sullivan D, Byrne S, O'connor MN, Ryan C, Gallagher P. STOPP/START criteria for potentially inappropriate prescribing in older people: version 2. Age Ageing. 2015;44(2):213218. doi:10.1093/ageing/afu189

12. Prazeres F, Santiago L. Prevalence of multimorbidity in the adult population attending primary care in Portugal: a cross-sectional study. BMJ Open. 2015;5(9):e009287. doi:10.1136/bmjopen-2015009287

13. Quinaz Romana G, Kislaya I, Salvador MR, Cunha Gonçalves S. Multimorbidity in Portugal: results from The First National Health Examination Survey. Acta Med Port. 2019;32(1):30-37. doi:10.20344/amp.11227

14. Eiras A, Teixeira MA, Gonzalez-Montalvo JI, Castell M-V, Queipo R, Otero A. [Consumption of drugs in over 65 in Porto (Portugal) and risk of potentially inappropriate medication prescribing]. Aten Primaria. 2016;48(2):110-120. doi:10.1016/j.aprim.2015.03.005
15. De Oliveira Martins S, Soares MA, Foppe Van Mil JW, Cabrita J. Inappropriate drug use by Portuguese elderly outpatients - effect of the beers criteria update. Pharm World Sci. 2006;28(5):296-301. doi:10.1007/s11096-006-9007-9

16. Simões PA, Santiago LM, Simões JA. Deprescribing in primary care in Portugal (DePil17-20): a three-phase observational and experimental study protocol. BMJ Open. 2018;8(7):1-6. doi:10.1136/bmjopen2017-019542

17. World Medical Association. World Medical Association Declaration of Helsinki: ethical principles for medical research involving human subjects. J Am Coll Dent. 2014;81(3):14-18.

18. von Elm E, Altman DG, Egger MSJP, Gøtzsche PC, Vandenbroucke JP, Initiative S. The Strengthening the Reporting of Observational Studies in Epidemiology (STROBE) statement: guidelines for reporting observational studies. J Clin Epidemiol. 2008;61(4):344-349. doi:10.1016/j.jclinepi.2007.11.008

19. PORDATA - Contemporary Portugal Database [homepage on the Internet]. Lisbon: Fundação Francisco Manuel dos Santos; 2009. Available from: https://www.pordata.pt/en/Home. Accessed February 19, 2018.

20. Patrao L, Deveza R, Martins H. PEM-A new patient centred electronic prescription platform. Procedia Technol. 2013;9:1313-1319. doi:10.1016/j.protcy.2013.12.147

21. Vademecum: DCI Em Português [homepage on the Internet]. Lisbon: INFARMED; 2005. Available from: http://www.infarmed.pt/docu ments/15786/17838/vademecum.pdf/f85294bb-db17-4d18-aaabf394fbbb963e. Acessed February 19, 2018.

22. Guaraldo L, Cano FG, Damasceno GS, Rozenfeld S. Inappropriate medication use among the elderly: a systematic review of administrative databases. BMC Geriatr. 2011;11:79. doi:10.1186/1471-231811-79

23. Hovstadius B, Åstrand B, Petersson G. Dispensed drugs and multiple medications in the Swedish population: an individual-based register study. BMC Clin Pharmacol. 2009;9:11. doi:10.1186/1472-6904-9-11

24. Saarelainen LK, Turner JP, Shakib S, et al. Potentially inappropriate medication use in older people with cancer: prevalence and correlates. J Geriatr Oncol. 2014;5(4):439-446. doi:10.1016/j.jgo.2014. 07.001

25. Shi S, Mörike K, Klotz U. The clinical implications of ageing for rational drug therapy. Eur J Clin Pharmacol. 2008;64(2):183-199. doi:10.1007/s00228-007-0422-1

26. Almeida TA, Reis EA, Pinto IVL, et al. Factors associated with the use of potentially inappropriate medications by older adults in primary health care: an analysis comparing AGS Beers, EU(7)-PIM list, and Brazilian consensus PIM criteria. Res Soc Adm Pharm. 2019;15 (4):370-377. doi:10.1016/j.sapharm.2018.06.002

27. Tamblyn RM, McLeod PJ, Abrahamowicz M, Laprise R. Do too many cooks spoil the broth? Multiple physician involvement in medical management of elderly patients and potentially inappropriate drug combinations. CMAJ. 1996;154(8):1177-1184.
Patient Preference and Adherence

\section{Publish your work in this journal}

Patient Preference and Adherence is an international, peer-reviewed, open access journal that focusing on the growing importance of patient preference and adherence throughout the therapeutic continuum. Patient satisfaction, acceptability, quality of life, compliance, persistence and their role in developing new therapeutic modalities and compounds to optimize clinical outcomes for existing disease states are major areas of interest for the journal. This journal has been accepted for indexing on PubMed Central. The manuscript management system is completely online and includes a very quick and fair peer-review system, which is all easy to use. Visit http:// www.dovepress.com/testimonials.php to read real quotes from published authors. 